\title{
Canada's health care system: A relevant approach for South Africa?
}

\author{
Anne-Emanuelle Birn, Stephanie Nixon
}

\begin{abstract}
Background. While countries such as the USA, South Africa and China debate health reforms to improve access to care while rationalising costs, Canada's health care system has emerged as a notable option. In the USA, meaningful discussion of the advantages and disadvantages of the Canadian system has been thwarted by ideological mudslinging on the part of large insurance companies seeking to preserve their ultra-profitable turf and backed by conservative political forces stirring up old fears of 'socialised medicine'. These distractions have relegated the possibility of a 'public option' to the legislative dustbin, leaving tens of millions of people to face uninsurance, under-insurance, bankruptcy and unnecessary death and suffering, even after passage of the Obama health plan. While South Africa appears to experience similar legislative paralysis, there remains room for reasoned health reform debate to address issues of equity, access, and financing.
\end{abstract}

Objective. Our aim is to contribute to the debate from a Canadian perspective, setting out the basic principles of Medicare (Canada's health care system), reviewing its advantages and challenges, clarifying misunderstandings, and exploring its relevance to South Africa. We periodically refer to the USA because of the similarities to the South African situation, including its health care system, which mirrors South Africa's current position if left unchanged.

Conclusion. While Medicare is neither flawless nor a model worthy of wholesale imitation, we contend that open discussion of Canada's experience is a useful component in South Africa's current policy and political efforts.

S Afr Med J 2010; 100: 516-520.

\section{'Of all the forms of inequality, injustice in health care is the most} shocking and inhumane.'

\section{Martin Luther King, Jr}

As various large countries (e.g. the USA, South Africa, China) debate health reforms about improved access to care while rationalising expenditures, Canada's health care system has emerged as a prominent option. In the USA, meaningful discussion on the advantages and disadvantages of the Canadian system has been thwarted by ideological mudslinging by defenders of large insurance companies seeking to preserve their ultra-profitable turf and backed by conservative political forces who have stirred up old fears of 'socialised medicine'. These distractions have relegated even the possibility of a 'public option' to the legislative dustbin, leaving tens of millions to face uninsurance, under-insurance, bankruptcy, and unnecessary death and suffering, even after passage of the Obama health plan.

While South Africa appears to be undergoing similar legislative paralysis, ${ }^{1}$ the opportunity still remains for reasoned health reform debate to address issues of equity, access, and financing. Our aim is to contribute to the debate from a Canadian perspective. We set out the basic principles of Medicare (Canada's health care system), review its advantages and ongoing challenges, clarify misunderstandings, and

Dalla Lana School of Public Health, University of Toronto, Canada Anne-Emanuelle Birn, MA, ScD

Department of Physical Therapy, University of Toronto, and Health Economics and HIV/AIDS Research Division (HEARD), University of KwaZulu-Natal, Durban Stephanie Nixon, $\mathrm{PhD}$ explore its relevance to South Africa. We periodically refer to the USA because of the similarities to the South African situation, including its health care system which mirrors South Africa's current position, if left unchanged (Table I). While Medicare is neither flawless nor a model capable of wholesale imitation, we contend that open discussion of Canada's experience is a useful component in South Africa's current policy and political efforts.

\section{Founding and principles of the Canadian health care system}

Until the 1940s, health care in Canada was primarily delivered through fee-for-service (i.e. direct payment to the service provider) private medical practice. Canada has a decentralised political system with 10 provinces and 3 territories. Regional efforts, starting with the province of Saskatchewan, began a 25-year struggle for national health insurance. Saskatchewan passed a public hospital insurance plan in 1947. After the federal government offered in 1957 to share the costs of providing hospital and diagnostic services, the rest of the country followed suit within 5 years. However, the real struggle proved to be public insurance for physicians' services, passed by the Saskatchewan legislature in 1962. Backed by the North American medical establishment, the province's doctors went on a 23-day strike to forestall the legislation, but the province prevailed and, by 1968, a national Medical Care Act was in place, providing federal funding to all provinces that passed universal hospital and medical care legislation. By 1972, Canada's universal health care system, named Medicare, was fully in place.

While this universal public health insurance plan was highly popular, serious concerns around equity surfaced within a few years because doctors and hospitals charged extra user fees for faster or special services. A review panel concluded 


\section{Table I. South Africa and the USA compared}

South Africa and the USA share imperatives for health reform; both use Canada as either a useful example or a punching bag ${ }^{2-5}$

- Both countries have vastly unequal two-tier systems where the elite enjoy unlimited care while millions are too poor to afford medical treatment

- Both countries viewed this inequality as a central issue in their recent national election campaigns

- The elected leaders in both countries promised voters that they would deliver a reformed health system to cover everyone regardless of income

- Efforts in both countries to achieve this promise have been bogged down by powerful resistance from lobby groups seeking to discredit Canada's Medicare system and to use their negative portrayal of Canada as an argument against universal health insurance

However, South Africa's health care system is more equitable than the USA system in many ways

- Progressive access to health care is a right in the South African Constitution, whereas the USA is one of a minority of countries in the world that rejects health as a human right

- Access to primary health care in the public health system is free at the point of access in South Africa

- Pregnant and breastfeeding women, children under 6, and people with disabilities have free and universal access to public hospitals across South Africa; the Medicaid 'safety net' programme in the USA only provides such access to certain means-tested populations, and varies by state

that the extra charges were leading to a de facto 2-tiered system that was limiting access to care. In 1984, parliament passed the Canada Health Act (one of the last actions of Prime Minister Pierre Trudeau's administration), setting out 5 principles underpinning Medicare (Table II).

Using federal funding as both carrot and stick, the Canada Health Act sought to ensure equity by penalising extra charges and creating an interlocking system of provincial and territorial health plans, even as financing and coverage vary (see below).

\section{How universal health insurance in Canada works}

Canada operates under a single-payer health care system. In contrast to South Africa or the USA, where both private insurance and government schemes co-exist, covered health care services in Canada are paid for through a single source: the provincial/territorial government. Table III summarises single-payer v. multiple-payer health systems.

In each province/territory, the Ministry of Health approves and funds a global annual operating budget for each hospital based on past budgets, patient load, inflation and salary increases, case mix, capital expenditure needs, and other factors. The global budget helps to control costs, as hospital administrators and department directors know they need to stay within the prescribed budget. When unforeseen events occur (e.g. severe acute respiratory syndrome (SARS) in 2003), the province reimburses hospitals that have incurred extra expenditures.

Physicians in private practice (the vast majority in Canada) are paid on a fee-for-service basis with a ceiling on earnings.
Fees are determined through negotiations between provincial medical associations and the corresponding Ministries of Health. Nurses' salaries are negotiated through collective bargaining. Hospital-based physicians and other health workers are paid salaries.

All legal residents of Canada are eligible for health insurance coverage after a minimal waiting period - usually a few months. In accordance with the Canada Health Act, residents with a health care card have access to all covered services with no extra payments or user fees. People in Canada can select their own doctors - a far cry from private insurance plans in the USA, which limit access to doctors according to an everchanging list.

\section{Financing}

Two-thirds of Medicare expenditure is funded by the province, based on a variety of mechanisms. General revenues (i.e. from income and corporate taxes) are an important source of revenue. Three provinces (Alberta, Ontario and British Columbia) use premiums based on a sliding income scale. Even those who have not paid the premium, however, are not denied access to health services. Other provinces raise revenues through lotteries and 'sin taxes' on alcohol and cigarettes.

Since 2004, the federal portion of funding has come in a dedicated block grant called the Canada Health Transfer, which the provinces must use for health care expenditure. On average, the transfer funds a third of health care expenditure. To take into account the fiscal disparities among provinces, the federal government also provides equalisation payments

\section{Table II. Principles of the Canada Health Act}

1. Public administration: The administration of the health care insurance plan of a province or territory must be carried out on a nonprofit basis by a public authority

2. Comprehensiveness: All medically necessary services provided by hospitals and doctors must be insured

3. Universality: All eligible persons* in the province or territory must be entitled to public health insurance coverage on uniform terms and conditions

4. Portability: Coverage for insured services must be maintained when an insured person moves or travels within Canada or travels outside the country

5. Accessibility: Reasonable access by insured persons to medically necessary hospital and physician services must be unimpeded by financial or other barriers 


\section{Table III. Organisation and effects of single-payer and multiple-payer systems compared}

Single-payer health care system (e.g. Canada)

- Raises funds, administers claims and shares costs across the population more efficiently and equitably

- One authority with an incentive and the capacity to contain costs

- No marketing expenses

- No need to estimate risks to establish differentiated premiums

- No profit paid to shareholders
Multiple-payer private health care system (e.g. USA)

- Overhead costs can be upward of 10 times higher among private insurers compared with a public single payer

- The larger the share of private health care financing, the more difficult it is to control expenditures (e.g. for-profit hospitals are $3-11 \%$ more expensive than non-profit hospitals)

- Employer-provided health insurance is a disincentive for labour mobility and hence negatively affects the allocation of labour

- As the cost of health insurance increases, so do costs to employers who provide health insurance, resulting in fewer salary increases, cuts in benefits, decreased employment levels, and more costs passed on to employees via higher premiums and co-payments and limits on coverage

- Premiums for those with chronic conditions are usually larger, placing a higher financial burden on the sick

- For-profit hospitals provide minimal care for the poor, leaving non-profits with a disproportionate financial responsibility

Source: Adapted from Birn A-E, Pillay Y, Holtz TH. Textbook of International Health: Global Health in a Dynamic World. 3rd ed. New York: Oxford University Press, 2009. Based on: Chernomas R. The Canadian health care system and the structural advantages of a single-payer system. University of Manitoba, unpublished manuscript; and Sepehri A, Chernomas R. Is the Canadian health care system fiscally sustainable? Int J Health Serv 2004; 34(2): 229-243.

to those provinces whose fiscal capacity is below the average of all 10 provinces. In 2009/2010, over \$Cdn 14 billion in equalisation transfers is being distributed to 6 provinces for health and other social spending. In addition, the three northern territories receive separate federal transfers (\$Cdn 2.5 billion in 2009/2010) for social services for their residents at a comparable level and tax rate as the provinces. Social service delivery in these regions is a considerable challenge because of the large number of small and isolated (snowbound for much of the year) communities.

In 2008, a total of $\$$ Cdn 172 billion was spent on health care in Canada, which is approximately $\$ 5170$ per capita. While among the highest levels in the world, partly owing to relatively high physicians' salaries, the $10 \%$ average of Canada's GDP that goes to health care is roughly one-third less than that of the USA. Furthermore, according to the Organisation for Economic Co-operation and Development (OECD), per capita spending on health care in Canada is $46 \%$ lower than in the USA. ${ }^{6}$ Almost a third of the higher spending in the USA is due to the multiple payer system bureaucracy (as in South Africa currently). Hospital and physician office billing administrative costs are more than three times higher in the USA than in Canada.?

The cost control advantages of Canada's single payer system are evident in Fig. 1. The USA and Canada had virtually the same pattern of health expenditure as a percentage of GDP until the early 1970s. But after Canada's national health insurance programme was fully implemented, it experienced far lower increases in health spending as a percentage of GDP than in the USA.

\section{Ongoing challanges}

\section{Limits to coverage}

In total, $70 \%$ of health care expenditure is publicly funded in Canada. Payers other than government (i.e. private insurance, employers and individuals) fund the remaining $30 \%$. This is because, notwithstanding the principles of universal coverage

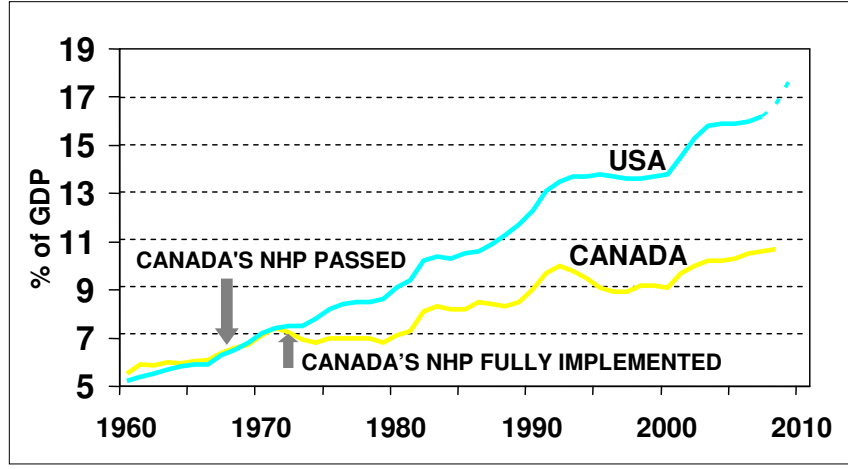

Fig. 1. Health care costs as percentage of GDP in Canada v. USA (1960 2010) (NHP = national health programme). Sources: courtesy of David Himmelstein and Steffie Woolhandler, tabulation of data from National Center for Health Statistics and Canadian Institute for Health Information. Thanks to Danielle Schirmer for preparing the figure.

and comprehensiveness under the Canada Health Act, not all medically necessary services are covered. While the omissions vary by province/territory, services typically left out include eye care (other than for minors and seniors), pharmaceuticals (except for seniors and people with disabilities), long-term care and dental care. These non-covered services have driven most of the rises in health expenditure as a percentage of GDP, with covered hospital, physician and administration costs remaining stable since Medicare was fully implemented.

\section{Brain drain}

Canada also experiences a shortage of medical personnel as does South Africa. The shortage of primary care personnel is particularly acute in many rural areas and among Canada's Aboriginal populations. Ironically, in Saskatchewan, which pioneered Medicare, $54 \%$ of doctors received their medical training overseas, and almost $20 \%$ of doctors were trained in South Africa alone. ${ }^{8}$ In that sense, there is a direct link between the future sustainability (and equity) of both Canada's and South Africa's health care systems.

While the shortage (or imbalanced distribution) of medical personnel in Canada undoubtedly indicates poor human 
resources training and management strategies, it is not a problem of Medicare per se. Rather, fault lies with national and regional educational and training policies, most notably an early 1990s policy reducing medical school enrolments by $10 \%$. As such, the shortage must be addressed at the political level, e.g. by raising the number of medical school entry slots, which in recent years have had more than 5 applicants for every medical school place, with large numbers of qualified candidates rejected. The nursing shortage has been even greater than the physician shortage, also leading to reliance on foreign health personnel. Canada has been in part responsible for the 100000 nurses who emigrated from the Philippines between 1990 and 2004; ${ }^{9}$ and some 50\% of Ghana's nurses have immigrated to Canada.

\section{Quality}

In the 1990s, waiting lists for non-emergency and specialist hospital services grew because government funding cuts led to the closing of $30 \%$ of hospital beds. The 2002 Commission on the Future of Health Care in Canada (the Romanow Commission) ${ }^{10}$ highlighted such flaws. Broad political consensus led to the disbursement of billions of federal dollars to the provinces to correct this problem, resulting in a dramatic drop in waiting times despite misleading claims by conservative think-tanks. Most importantly, health systemdependent health outcomes and quality of care are notably better in Canada than in the USA. ${ }^{11}$

\section{Equity}

Equity considerations include how fairly a health system's resources are financed and distributed, and what role the health system plays in improving equity in society generally.

Canada's national health insurance system is designed to be equitable in both its financing arrangements and its coverage guarantee. While access and resource availability are problematic among rural and northern populations, the federal government and provinces are attempting to redress this problem. In 2005, the Northern Ontario School of Medicine was founded, specifically to attract students from northern and Aboriginal backgrounds to train in community health. As the country's first school of medicine with a social accountability mandate, it is committed to serving rural and remote populations.

At the same time, the Canadian system's principles of universality are being challenged. A 2005 court case in Quebec opened the door for private insurance and private clinics to cover publicly available services that are not available timeously. Because of the Canada Health Act's prohibition on extra billing if provinces want to receive federal subsidies, 6 provinces (including Quebec) have passed laws that prohibit private insurance for medically necessary services that are covered by provincial health insurance.

So far, the importance of maintaining equitable, universal public health insurance has impeded the creation of a twotier medical care system. But popular support for Medicare hinges on citizen and provider participation in identifying and addressing weaknesses of the system as well as in government responsiveness to improving the quality of services. The federal investment in reducing waiting times in the wake of the Romanow Commission is an example of how broad participation in health policy-making has helped to strengthen Medicare. Any health system must undergo continuous reform to meet shifting population needs and evidence-based developments in medicine and public health services.

The second aspect of equity concerns the role played by the health system in reducing social inequalities (in health). South Africa is one of the most unequal societies in the world, with the richest tenth of the population receiving over half of all income, and the poorest tenth accounting for just $0.2 \%$ of income. ${ }^{12}$ Inequality extremes in Canada are about half of those in South Africa, yet poverty - especially the proportion of children living in poverty - remains entrenched above $10 \%$. Nevertheless, Canada's social welfare system, including income transfers for the elderly and the health care system, has played a significant role in promoting equity.

Social class and racial/ethnic patterns of health expenserelated bankruptcies and deaths linked to lack of coverage in the USA provide evidence for the role of health insurance and social welfare programmes generally in reducing social inequalities in health. Medical debts in 2007 made up over 62\% of all bankruptcies, up from $46 \%$ just 6 years earlier. ${ }^{13}$ Lack of health insurance is estimated to result in approximately 18000 deaths per year in the USA. ${ }^{14}$ Eliminating such sources of inequality should serve as a key incentive for any reform of the health care system in South Africa.

\section{Relevance of the Canadian experience to South Africa}

South Africa faces considerable health problems, including rising child mortality and high rates of HIV/AIDS and tuberculosis. These stem from broader societal determinants of health (including poor housing conditions, low wages, unemployment, systemic poverty and inadequate schooling), that can only be partially addressed by the health care system. Health care is but one determinant of health. Nevertheless, a well-functioning and equitable health care system is crucial for society, and health reform in South Africa has gained symbolic value as a sign of socio-political change.

On the surface, it is easy to identify differences between Canada and South Africa that challenge the relevance of a Medicare model in a South African context. A key difference, for example, is the labour force structure in the 2 countries: the proportion of South Africans employed in the formal sector (and hence South Africa's tax base) is far smaller than in Canada. Yet significant parallels between South Africa and Canada inform reflection on the Canadian system during South Africa's health reform deliberations. Over half of South Africa's total health expenditure is spent in the private sector. ${ }^{15}$ Canada's health system was also mostly private before Medicare evolved. South Africa's health governance comprises 1 national and 9 provincial departments of health, based on a district model. Canada's health system is also decentralised, with supervision provided at the federal level and health services administered and delivered by the provinces and territories. 
Like South Africa today, health service provision and health system-related outcomes in Canada before Medicare varied dramatically across its provinces and territories. This inequity has been largely addressed under Medicare. Canada and South Africa have hard-to-reach populations in rural areas that require special targeting within a universal system. Labour unions are influential in both countries, and it is noteworthy that the national health programme has consistently received impassioned support from Canada's labour representatives, as in South Africa. ${ }^{16}$ Both countries share an explicit commitment to equity for all citizens, which includes focusing on the poorest and most vulnerable in our societies. To this end, not only has Canada's universal health system provided a vehicle for promoting equity, but the principles of Medicare have also become a central part of the Canadian identity.

Perhaps most compelling is the fact that Canada's universal health care system required 25 years of struggle by advocates within government and progressive political parties, the health sector, patient groups, labour unions, certain sectors of business and, importantly, the general population. Medicare was built by Canadians, and requires the ongoing participation of citizens to ensure its relevance as the needs of the diverse population and discoveries in medicine evolve.

The political change witnessed during the advent of Canada's Medicare, however, is dwarfed by the accomplishments of South Africa in the last two decades. Specifically, since 1994, South Africa has made remarkable gains in terms of health care access, including efforts to redress historical inequities and provide essential care to disadvantaged populations. ${ }^{17}$ The drive to transform South Africa's health care system into one based on equity and a sustainable financial model has been underway since the ANC's health plan was launched 15 years ago. Current deliberations have the opportunity to build on this history of achievements and contribute not only to the health of residents but also to the well-being of the country. The Canadian approach is not a panacea for South Africa, yet lessons may be found in its fundamental principles and funding structures, which can inform South Africa's quest for a fair, effective and equitable health care system.

In 2004, the South African Broadcasting Corporation (SABC) conducted a nationwide poll to determine "The Greatest South African' of all time. The winner, unsurprisingly, was Nelson Mandela. Something that current South African President Jacob Zuma might consider is that in the same year, the Canadian
Broadcasting Corporation (CBC) conducted a parallel poll in Canada. Tommy Douglas, best known as the father of Canada's national health insurance programme, was voted 'The Greatest Canadian' of all time. ${ }^{18}$

The authors are grateful to Robert Chernomas and Mark Hunter for their helpful comments. Anne-Emanuelle Birn's work on this article was supported, in part, by the Canada Research Chairs programme, which had no role in the writing of the article or the decision to submit it for publication.

\section{References}

1. Zille enters NHI debate. Health-e 18 June 2009. http://www.health-e.org.za/news/article. php?uid=20032357 (accessed 19 October 2009).

2. York G. Can South Africa copy Canada's medicare? Globe and Mail 11 August 2009

3. Davie E. Stepping carefully towards health reform. Health Policy Unit. http://www. healthpolicyunit.org/scripts/documents/showDocument.asp?docId=349 (accessed 14 February 2010).

4. Mchangama J. Beware the blind alley of the 'right' to health. Business Day 4 January 2010. http://www.businessday.co.za/articles/Content.aspx?id=90598 (accessed 14 February 2010).

5. Esmail N, Walker M. High-priced Canadian health care system fails patients. Health Policy Unit. http:// www.healthpolicyunit.org/scripts/documents/showDocument.asp?docId=194 (accessed 14 February 2010)

6. Organization for Economic Cooperation and Development. OECD Health Data 2009: How does Canada compare. http://www.oecd.org/dataoecd/46/33/38979719.pdf (accessed 19 October 2009).

7. Woolhandler S, Campbell T, Himmelstein DU. Costs of health care administration in the United States and Canada. N Engl I Med 2003; 349: 768-775

8. Labonte R, Packer C, Klassen N, et al. The brain drain of health professionals from subSaharan Africa to Canada. In: African Migration and Development Series No. 2 (South African Migration Project-SAMP). Cape Town: Idasa Publishing, 2006.

9. Joint Learning Initiative. Human Resources for Health: Overcoming the Crisis. Cambridge, MA Harvard University Press, 2004

10. Romanow RJ. Building on Values: The Future of Health Care in Canada. Ottawa: Government of Canada Publications, 2002. http://www.hc-sc.gc.ca/hcs-sss/hhr-rhs/strateg/romanow-eng. php (accessed 18 October 2009)

11. Guyatt GH, Devereaux PJ, Lexchin J, et al. A systematic review of studies comparing health outcomes in Canada and the United States. Open Medicine 2007; 1(1): e27-e36.

12. Coovadia H, Jewkes R, Barron P, Sanders D, McIntyre D. The health and health system of South Africa: historical roots of current public health challenges. Lancet 2009; published online 25 August 2009. DOI:10.1016/S0140-6736(09)60951-X.

13. Himmelstein DU, Thorne D, Warren E, Woolhandler S. Medical bankruptcy in the United States, 2007: results of a national study. Am J Med 2009; advance e-print.

14. Institute of Medicine. Insuring America's Health: Principles and Recommendations. Washington, DC: The National Academies Press, 2004. http://www.iom.edu/Reports/2004/InsuringAmericas-Health-Principles-and-Recommendations.aspx (accessed 12 April 2010).

15. Chopra M, Daviaud E, Pattinson B, Fonn S, Lawn JE. Saving the lives of South Africa's mothers, babies, and children: can the health system deliver? Lancet 2009; published online 25 August. DOI:10.1016/S0140-6736(09)61123-5.

16. General Motors, Ford and Daimler-Chrysler and the Canadian Auto Workers. General Motors, Ford and Daimler-Chrysler and the Canadian Auto Workers Support Canadian Medicare: Joint Letter on Publicly Funded Health Care 12 September 2002; and Congress of South African Trade Unions (COSATU) Support for NHI (2000). http:/ / www.cosatu.org.za/ show.php?include=docs $/$ policy $/ 2000 /$ ssaudit.htm\#central (accessed 19 October 2009).

17. Coovadia H, Jewkes R, Barron P, Sanders D, McIntyre D. The health and health system of South Africa: historical roots of current public health challenges. Lancet 2009; published online 25 August. DOI:10.1016/S0140-6736(09)60951-X.

18. The Greatest Canadian. http://en.wikipedia.org/wiki/The_Greatest_Canadian (accessed 19 October 2009).

Accepted 22 February 2010. 